\title{
A framework for sustainable and circular system design: Development and application on thermal insulation materials
}

\section{Journal Article}

Author(s):

Wiprächtiger, Maja; Haupt, Mélanie (1); Heeren, Niko (1); Waser, Eliane; Hellweg, Stefanie (1)

Publication date:

2020-03

Permanent link:

https://doi.org/10.3929/ethz-b-000387145

Rights / license:

Creative Commons Attribution-NonCommercial-NoDerivatives 4.0 International

Originally published in:

Resources, Conservation and Recycling 154, https://doi.org/10.1016/j.resconrec.2019.104631

\section{Funding acknowledgement:}

172456 - Towards A sustainable CircuLar Economy - Combining a material flow with a business and policy perspective (TACLE) (SNF) 
(C) $<2020>$. This manuscript version is made available under the CC-BY-NC-ND 4.0 license

https://creativecommons.org/licenses/by-nc-nd/4.0/

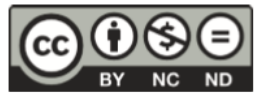

Accepted version.

This document is the published as: Wiprächtiger, M., Haupt, M., Heeren, N., Waser, E., and Hellweg, S. A framework for sustainable and circular system design: development and application on thermal insulation materials. Resources, Conservation \& Recycling. (2020)

https://doi.org/10.1016/j.resconrec.2019.104631

Originally uploaded to https://esd.ifu.ethz.ch/the-group/people/person-detail.wipraechtiger.html on 10.12.2020

\section{A framework for sustainable and circular system design: Development and application on thermal insulation materials.}

Maja Wiprächtiger ${ }^{\mathrm{a},{ }^{*}}$, Melanie Haupt ${ }^{\mathrm{a}}$, Niko Heeren ${ }^{\mathrm{a}, \mathrm{b}}$, Eliane Waser ${ }^{\mathrm{c}}$, and Stefanie Hellwega

a: ETH Zurich, Institute of Environmental Engineering, John-von-Neumann Weg 9, CH-8093 Zurich, Switzerland

b: School of Forestry \& Environmental Studies, Yale University, 380 Edwards St., New Haven, CT 06511, USA,

c: TBF + Partner AG, Planer und Ingenieure, Beckenhofstrasse 35, Postfach 8042 Zürich, Switzerland

* Corresponding author: Maja Wiprächtiger, tel.: +41 4463376 39, email:

wipraechtiger@ifu.baug.ethz.ch 


\section{Abstract}

Circular economy is increasingly promoted as a solution to decouple economic growth and environmental impacts. To design a circular and sustainable system, a structured approach is needed. In this study, we suggest to follow a 3-step approach. First, the status quo is evaluated using environmental assessment methods. We determine current circularity (share of assessed product and materials retained and further used in the system), environmental impacts, the most impactful products and processes, and assess contaminants and impurities. Second, scenarios favoring circularity strategies are developed and their environmental impacts evaluated. Third, the scenarios are compared and measures for environmental impact mitigation derived.

The suggested approach was applied to the case study of thermal insulation in residential buildings in Switzerland. Coupling dynamic, prospective material flow analysis with life cycle impact assessment enabled to determine current and future environmental impacts. Current material circularity is low due to lacking incentives for recycling and legally required incineration of flame retardant containing oil-based materials. The most impact-intensive processes were the production of insulation materials and the incineration of oil-based materials including their adhering residues. The investigated scenarios include (i) increased recycling, (ii) augmented use of biogenic materials, and (iii) a combination thereof. All scenarios lead to reduced climate change and human toxicity impacts. The second and third scenarios showed increased impacts for land use, ozone depletion, and ecotoxicity. Taking into consideration end-of-life already in the design process, phasing out toxic materials and increasing usage of renewable materials are crucial for sustainable, circular system design.

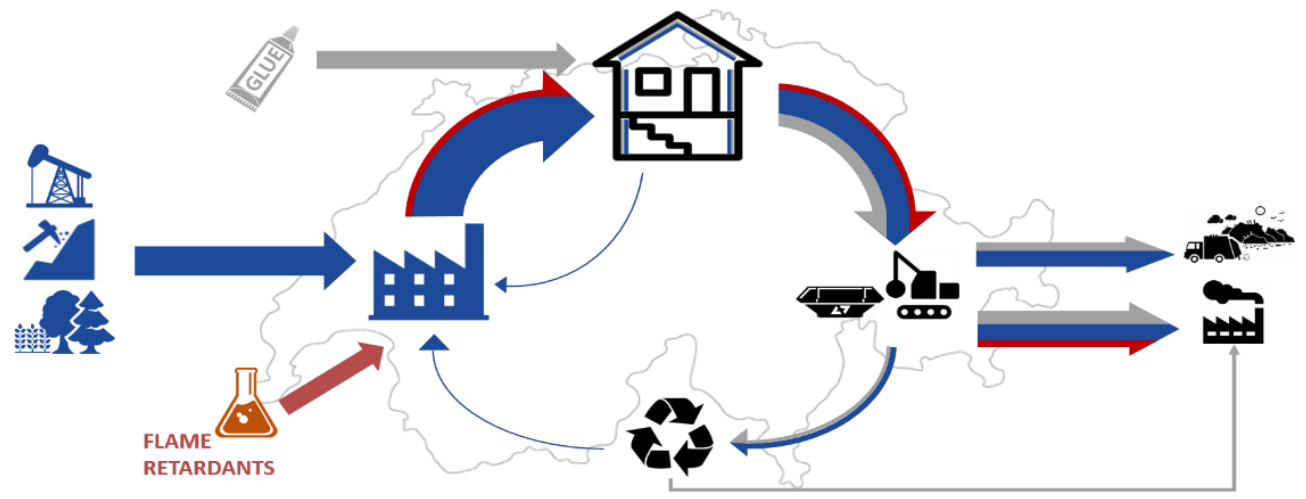

Key words: circular economy, sustainability, life cycle assessment, circular design, recycling 


\section{Introduction}

Natural resource extraction and processing has increased more than three fold since 1970, causing more than $50 \%$ of the current global greenhouse gas (GHG) emissions (IRP 2019). To reduce environmental impacts whilst maintaining economic prosperity and human well-being, environmental impacts and natural resource consumption need to be decoupled from economic activities (UNEP, 2011). One approach for decoupling, promoted by the Ellen MacArthur foundation and the United Nations Environmental Program (UNEP), is circular economy (CE). CE aims at closing resource loops by reusing or recycling goods and materials and, therefore, minimizing waste (Ellen MacArthur Foundation, 2013; UNEP, 2018).

There are many definitions for 'circular economy' (Kirchherr et al. (2017), Ghisellini et al. (2016), Winans et al. (2017), Homrich et al. (2018)). Kirchherr et al. (2017) identified 95 different definitions in the literature, which in some cases vary greatly. Here, we understand CE as a concept that includes the 10 circularity strategies (R0: refuse, R1: rethink, R2: reduce, R3:re-use, R4: repair, R5: refurbish, R6: remanufacture, R7: repurpose, R8: recycle, R9: recover, based on Potting et al. (2016)). CE covers different levels (materials, products, but also consumers, eco-industrial parks, cities, nations, global) and links to sustainable development of environmental quality, economic prosperity and social equity (Kirchherr et al., 2017).

Zink and Geyer (2017) warned of potential rebounds of CE, as higher efficiency can lead to increased overall production, resulting in elevated environmental impacts. Moreover, the closed-loop recycling concept associated with CE does not necessarily have lower environmental impacts than open-loop recycling (Haupt et al., 2018). Other aspects, such as contaminations and impurities in secondary resources, should be considered as well when striving to make the economy more circular (Hahladakis and Iacovidou, 2018; Haupt and Zschokke, 2017; Leslie et al., 2016; Pivnenko et al., 2016). Circulating materials in society requires a comprehensive clean cycle strategy, where contaminants and impurities, but consequently also the material itself, are eliminated from the system, e.g. through incineration (Brunner and Rechberger, 2015; Kral et al., 2019, 2013).

To assess CE, different tools have been proposed and applied, most prominently material flow analysis (MFA) and life cycle assessment (LCA) (Brunner and Rechberger, 2010; Haupt and Zschokke, 2017; Hellweg and Milà i Canals, 2014). MFA is a useful tool that can help to assess anthropogenic material flows and stocks. It can reveal opportunities for improved recycling and be used to monitor e.g. recycling targets. LCA can be used for the assessment of the environmental performance of systems (see for example Haupt and Hellweg, (2019); Huysman et al. (2017)). Other assessment methodologies, as reviewed by Cobo et al. (2018), include life cycle costing (for example (Martinez-Sanchez et al., 2015; Massarutto et al., 2011) and 
the analysis of energy flows (Tonini et al., 2014). Additional methods include the combination of LCA and optimization for minimized life cycle costs (Martinez-Sanchez et al., 2017), economic and environmental optimization (Münster et al., 2015), the combination of LCA with waste and energy scenarios (Meylan et al., 2018), the optimization of waste stream distribution using the urban biorefinery concept, (Satchatippavarn et al., 2016) and the combination of MFA, LCA, and multi-objective optimization (Vadenbo et al., 2014b, 2014a). While the above-mentioned methods can be used for the assessment of CE aspects, a comprehensive and structured method for the design of systems that embraces the facets of CE whilst reducing environmental impacts is currently lacking. In this study, we aim to develop a method for sustainable circular system design (SCSD) that environmentally assesses systems, derives measures to increase the circularity of the system, and finally evaluates the derived measures' sustainability. The method draws from the pool of possibilities CE offers, such as for example circularity strategies within the production chain (R0-R9), waste hierarchy, material quality aspects, and product design considerations, to design systems with improved resource utilization and minimal ecological damage (Bocken et al., 2016; Brunner and Rechberger, 2015; Haupt et al., 2017; Kral et al., 2019, 2013; Pauliuk et al., 2017; Potting et al., 2016). To ensure not only circular design but also reduced environmental impacts, the method builds on and integrates existing environmental assessment tools.

The developed SCSD methodology will be tested on a selected system in Switzerland. Switzerland is highly committed to reduce its per capita $\mathrm{CO}_{2}$ emissions by $50 \%$ by 2030 and even believes a reduction of up to $75 \%$ until 2050 is possible (BAFU, 2018). Around 30\% of these emissions are caused by the building sector (BAFU, 2018), which also contributes $40 \%$ to the total energy consumption (UVEK, 2017). A recent study shows that, although negligible in terms of mass, thermal insulation materials are highly relevant in terms of environmental impacts (Heeren and Hellweg, 2019). Due to the presence of hexabromcyclododecan (HBCD), a flame retardant previously used in oil-based materials, the recycling of insulation materials is still rather uncommon in Switzerland (Brupbacher and Rubli, 2016). HBCD is a persistent organic pollutant (POP) and was banned from use as flame retardant in insulation materials in 2015 (Kasser et al., 2013). Based on the long life spans of insulation materials, HBCD containing materials are expected to remain present in waste streams for a long time. Therefore, a HBCD removal process is required to enable safe recycling of HBCD contaminated insulation material (Schlummer et al., 2017).

Jakob et al. (2016) and Heeren and Hellweg (2019) expect that insulation material inflows and outflows will be equilibrated by 2055 due to reduced population growth and expiring lifetimes of buildings, leading to larger waste flows and less demand for new housing. The larger waste flows pose challenges to the current waste management system but also opportunities for redesigning the system and closing material loops. Current installation practice and the former use of toxic flame retardants hinder recycling. New 
designs for recycling or even reuse-friendly installation and deconstruction, phasing out of toxic substances, but also the cascading use of biogenic materials are possibilities for circular and sustainable design. The system of thermal insulation materials in Swiss residential buildings hence offers a great opportunity to test the suggested SCSD assessment.

\section{The sustainable circular system design (SCSD) method}

To derive a systematic approach for SCSD, existing environmental assessment methods are combined with $\mathrm{CE}$ aspects. The proposed methodology has three phases described in detail in this chapter.

\subsection{Phase 1: Status Quo Assessment}

Phase 1 entails the environmental assessment of the chosen system. We propose to use the modular MFA/LCA approach by Haupt et al. (2018). An MFA is conducted to identify and display the flows and stocks of the assessed system. Besides the target material, contaminants and residues need to be modeled. Based on the material flows, the system's circularity can be determined. In the context of this publication, we understand circularity as a measure of the share of products and materials repeatedly used in the system. Products can be preserved in the system through reuse, repair, refurbishment, and remanufacturing. Material cycling is facilitated through recycling processes (Potting et al., 2016). The metric used to determine the circularity depends on the nature and number of applied value retention processes (see Equation 1).

$$
\text { circularity }=\frac{\text { mass of product retained }+ \text { mass of material recycled }}{\text { total mass of material entering the waste management system }}
$$

In order to establish a direct link to the LCA, the flows and processes are translated into a product-processmatrix (Haupt et al., 2018), and each process is attributed its related environmental impacts (LCA modules). The direct link between MFA and LCA allows quantifying changes in environmental impacts due to variation of material flows (Haupt et al., 2018). Both MFA and LCA include production, use, and end-oflife of the products within the system, to allow for deriving measures at every step of the life cycle. The functional unit for both MFA and LCA should consider the service the investigated system provides over a determined time span (Weidema et al., 2004). To account for secondary material substituting primary material, user-specific, institutionally prescribed, and technical functionalities should be considered as suggested by Vadenbo et al. (2017).

The aim of phase 1 is to determine the system's circularity, to identify all processes and material flows, to calculate the environmental hotspots and to outline improvement potentials to be investigated in phase 2 . 


\subsection{Phase 2: Scenario Development}

In phase 2, scenarios for environmental impact mitigation are developed. The scenarios consider options for impact reduction within the technical cycle (e.g. improved recycling) but also within biological cycles (e.g. cascading use of wood) (Ellen MacArthur Foundation, 2013). Other options are replacing nonrenewable with renewable materials (e.g. replacing single use plastic cups with cardboard cups), introducing options for material-contaminant separation, and using products made of waste materials (e.g. foam glass insulation made of used packaging glass). We strongly recommend the involvement of experts and policy makers to develop relevant and meaningful scenarios. The scenarios should also be tested in terms of their feasibility, e.g. with regard to the availability of the biogenic material in a sustainable manner. Using the previously described modular MFA/LCA method, the changes in environmental impacts for the different scenarios are calculated.

To evaluate the future effects of the scenarios, we recommend conducting a prospective MFA/LCA. For materials with long life spans, this would be a dynamic MFA/LCA. The chosen time horizon of the assessment depends on the lifespan of the materials, as the effects of the scenarios are not visible until the material life span has been reached (e.g. phasing out of oil-based materials). When modelling prospective scenarios for decision-making, the consequences of a system change also needs to be considered. This calls

for a consequential LCA approach (Ekvall and Weidema, 2004). For this, marginal technologies that consider market aspects and the investigated material need to be identified. This may involve considering the forecasted local market changes and geographically specific technological developments.

The aim of phase 2 is to develop scenarios that comply with CE strategies. To determine whether the developed scenarios are circular and sustainable, they are evaluated with environmental assessment methods.

\subsection{Phase 3: Derivation of Environmental Impact Mitigation Strategies}

In phase 3, the derived scenarios are compared in terms of their environmental impacts, legal feasibility, profitability, and social acceptance. Depending on the outcome of the assessment's results, new scenarios need to be developed. Phase 2 and 3 are thus applied iteratively to find the optimal solution. To test the assumptions and determine critical parameters, a sensitivity analysis is conducted.

Based on the status quo assessment in phase 1 and the thereof derived scenarios of phase 2, the aim of phase 3 is to identify the strategy with highest impact reduction. 


\section{Application of the SCSD method on a selected case study}

\subsection{Phase 1: Status Quo Assessment}

Following the first step of the SCSD assessment (section 2.1), the MFA of the insulation material in Swiss residential buildings was modelled for the year 2015. The time series of insulation material inflow and outflow by building component (roof, wall, ceiling, etc.) was derived from Heeren and Hellweg (2019), who estimated the material volumes in Swiss residential buildings using GIS data for building footprints and height. Using a stochastic approach by using lifetime distributions of different materials, the study projects annual material in- and outflow of the building stock for the period 2015-2055 (see Tables S7S12). Six materials, which cover $95 \%$ of the Swiss insulation market, were considered: three oil-based materials (extruded and expanded polystyrene and polyurethane foam), two mineral wools (glass wool and stone wool), and one bio-based insulation material (wood fiberboard). In phase 2, (Section 3.2) foam glass, hemp fibers, and cellulose fibers were additionally considered.

The insulation material system comprises the insulation materials, residues, and contaminations in the insulation material (see SI 1, Chapter 1.3). For insulation material that enters the recycling process, it was assumed that residues of adhesives were separated from the insulation material. The subsequent transport and thermal treatment of the residues to municipal incineration plants, as well as the energy recovery from incineration, was modeled (see Figure 1). For disposal pathways other than recycling residues were assumed to enter the same treatment processes as the insulation material. It was assumed that all expanded and extruded polystyrene (EPS and XPS, respectively) installed between 1980 and 2015 contained the chemical HBCD. Polyurethane foams (PUR) typically contained a different brominated flame retardant, pentabromodiphenyl ether (PBDE) (Morf et al., 2007). Similar to HBCD, PBDE has been classified as a persistent organic pollutant and its production and use is forbidden (UN Environment, 2017). EPS, XPS, and PUR can therefore not be recycled without first removing hazardous flame retardants from the insulation material. 
For the modelling of the deconstruction process the insulation materials were assumed to be separated and collected in combustible, inert, mixed, or single material troughs (Figure 1) (Waser, 2017). Two practices can be distinguished: (1) Conventional deconstruction, which entails deconstruction without single-origin separation of materials, and (2) selective dismantling, where the façade is deconstructed layer by layer, enabling a better separation and hence higher amounts of material collected in single material troughs. Only insulation material collected from single material troughs enters the recycling process (Waser, 2017).

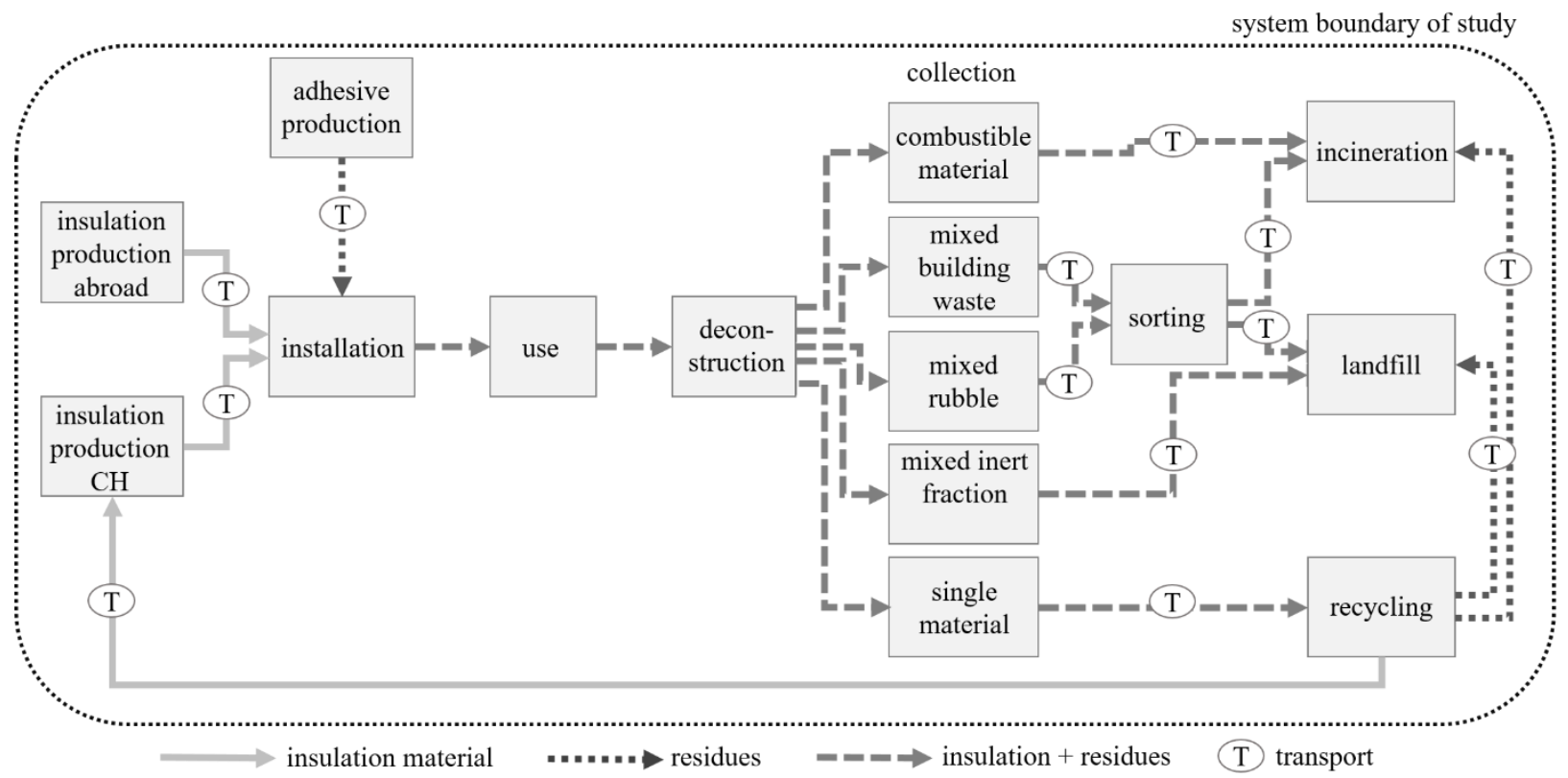

Figure 1: Schematic overview of processes, material flows, transport, and system boundary of the thermal insulation material case study.

The current recycling scheme for EPS involves the purchase of recycling bags by the deconstruction company, which can then be brought back to the production company. There, the EPS is crushed to granulate and stored until further used in the production of EPS (Waser, 2017). Neither XPS nor PUR insulations are currently recycled in Switzerland. Stone wool recycling works similarly to the EPS recycling scheme, clean cut-offs and sorted deconstructed stone wool parts are brought back to the only stone wool producer in Switzerland. Here, the insulation is separated from residues, milled, mixed with production waste, and pressed into briquettes at a nearby company before being added into the melting oven and reprocessed into stone wool insulation (Waser, 2017). The current collected glass wool amounts are very low and can be directly added as flakes to newly produced mats. For the recycling of large amounts of glass wool an additional melting process in an oxymelt oven is required to obtain glass cullets that are then melted and extruded to glass wool mats again (ISOVER St. Gobain, 2018). Wood fiberboard insulation is often used in a cascade; it is made of waste wood chips and after use as insulation can either be used for energy 
production, composted or clean cut offs from the fiberboards can be shredded and the resulting wood chips reused in the insulation production again (PAVATEX SA, n.d.; Villiger, 2018).

As selective dismantling is more time-intensive and thus more costly, it is not as widespread as conventional deconstruction. Hence, material is collected in the mixed, combustible, or inert fraction rather than in single material troughs. Today, the largest amount of insulation material is either incinerated or landfilled and only a small quantity is recycled. From a legal point of view, oil-based materials must be incinerated, and mineral wools landfilled. However, since separation is often difficult, a small share of oil-based materials ends up in landfills, and a small share of mineral wools is incinerated (Brupbacher and Rubli, 2016). The modeling and visualization of results from the MFA were conducted in STAN and circular Sankey (Cencic and Rechberger, 2008; Pauliuk and Hasan, 2017), as shown in Figures 2 and 4 and Figures S2 and S3.

In this case study, the only process contributing to circularity was recycling. We measured the system's circularity as described above (Equation 1). The circularity was calculated by comparing the ratio of the amount of insulation material recycled with the amount of insulation material deconstructed.

To ensure a fair comparison between the impacts of different materials, the impacts were normalized to one square meter of reference-insulation material with a fixed heat conductivity (lambda) of $0.035 \mathrm{~W} / \mathrm{m} \cdot \mathrm{K}$ and a thickness of $0.2 \mathrm{~m}$. To achieve the same insulation performance, the thickness and hence mass of the other materials were adjusted (considering the specific densities of the materials under investigation, as documented in Table S1, SI 1). The functional unit used for the assessment of future scenarios was 'the thermal insulation system added to, and deconstructed from, Swiss residential buildings in one year'. The LCA was built modularly following the approach of Haupt et al. (2018). The life cycle inventories (LCI) used were taken from the database ecoinvent 3.3, allocation cut-off (Wernet et al., 2016) or compiled manually (see SI 2 for all LCIs). Emissions from the incineration of insulation material and residues were calculated using the tool LCA4waste (Boesch et al., 2014). All calculations were made with the software Brightway (Mutel, 2017).

Climate change impact was previously determined to be a key impact category for insulation materials (Asdrubali et al., 2015; Kymäläinen and Sjöberg, 2008; Schiavoni et al., 2016; Zampori et al., 2013) and was considered here using the IPCC model for climate change (IPCC, 2013). If biogenic materials are considered in long-term applications, the impact of carbon sequestration should be included. Carbon sequestration is important, as during the use phase of biogenic materials, re-growing biomass takes up and stores carbon. Delaying the release of carbon to the atmosphere avoids impacts caused by elevated carbon concentrations in the atmosphere (Brandão et al., 2013). Following the approach of Guest et al. (2013) the 
rotation period of the plant and the storage time of the final product in the system are determined to obtain global warming potential factors for carbon sequestration.

Additionally, the impacts on human and ecotoxicity were evaluated using the UNEP-SETAC USEtox method (Rosenbaum et al., 2008). Land use and terrestrial eutrophication were assessed because they may be relevant for the biogenic materials, and ozone layer depletion to account for hydro- or chlorofluorocarbons (HFCs, CFC) commonly used in XPS production (European Commission, 2011). As the impact on climate change was determined to be the key parameter for insulation materials, only these results are presented in the results (section 4). The results for the other impact categories can be found in Figures S4 - S9 in the SI.

\subsection{Phase 2: Development of Scenarios}

Based on the assessment of the current system's circularity by MFA and identification of environmental hotspots by LCA, three possible future scenarios were developed and compared to the baseline scenario. The shares of the different insulation materials were extrapolated for the years 2035 and 2055 based on the development between 1980-2015 (Jakob et al. 2016) (see Figure S1 and section 1.2 in SI 1 for detailed information on extrapolation). The shares of materials going into single material collection, incineration, landfilling, recycling, etc. were extrapolated from 2015, while considering the changing shares of the insulation material types in the waste stream as a function of historic developments. The baseline scenario is, therefore, the continuation of current trends, as observed in 2015 until 2055.

The environmental impacts were assessed for the time horizon 2015 - 2055 using dynamic models for the years 1980 - 2015. To account for changes in the electricity mix and heat supply until 2035 and 2055, a marginal electricity mix was determined. We assumed that when striving to reach a more sustainable and circular economy, energy and heat demand would be covered by renewable energy sources (Ellen MacArthur Foundation, 2013). To determine the renewable energy source that could cover additional energy and heat demand, the reports from the Federal Office of Energy, scenario 'Political Measures', were compared to the Greenpeace report 'energy [r] evolution'. The Greenpeace report is more ambitious than the federal study. The as-of-yet untapped energy sources, i.e. the differences in e.g. biomass utilization between the reports, were identified (Bundesamt für Energie (BFE) 2007, Kirchner et al. 2012, Greenpeace 2015). The marginal electricity mixes for both years (2035 and 2050) consist, therefore, of electricity produced from biomass (25\%) and photovoltaics (75\%) and heat produced from biomass. 
The first scenario includes an increase of insulation recycling through improving separate collection and implementation of a separation process to recover flame retardants from insulation materials. The second scenario assumes the substitution of oil-based materials with biogenic and mineral materials. The third scenario is a combination of the other two: substitution of oil-based materials with more sustainable renewable materials where possible and otherwise increased recycling of oil-based materials.

\subsubsection{Assumptions for 'increased recycling rate' scenario}

As current material circularity was determined to be low, options for increased future recycling as of 2020 were investigated. In this scenario, recycling refers to the preservation of the main components of insulation materials. For oil-based materials, this is the polystyrene and the polyurethane. For the mineral and wood fiber materials, the minerals and wood, without the binding material, is preserved. To enhance insulation material recycling it was assumed that all houses are selectively dismantled, enabling a better separation of the materials. Further, it was assumed that (i) oil-based materials are no longer landfilled, (ii) mineral materials are no longer incinerated, and (iii) that, due to better separation during deconstruction, around $75 \%$ of the insulation material are collected in single material troughs of which $90 \%$ are brought to recycling (see SI 1, chapter 2.2, for more information). To determine the amount of HBCD contaminated material, the outflow of material installed before 2015 was calculated from the building stock model (Heeren and Hellweg 2019). These materials required further treatment. The CreaSolv® process was assumed to be used to separate polystyrene and flame retardants (Freegard et al., 2006). During the separation process, the material is first shredded and then dissolved in a solvent. The HBCD remains in the precipitated polystyrene, requiring an additional extraction step. After the extraction, the extracted HBCD is sent to a bromine recovery unit and the polystyrene granulate can be reused. The solvent can be recovered and applied in the process again (Schlummer et al., 2017).

\subsubsection{Assumptions for 'increased use of renewable materials' scenario}

For the renewable materials scenario it was assumed that oil-based insulation materials were phased out as of 2020. Instead, biogenic materials are used in a cascade, with insulation material being the penultimate use before energy recovery (Ellen MacArthur Foundation, 2013). The renewable insulation materials chosen were wood, cellulose, and hemp fibers. Wood fiber as insulation is already used in Switzerland, but not to a large extent (Jakob et al., 2016). Since only a small amount of waste paper in Switzerland is currently used for insulation material production (Haupt et al., 2016), a large additional potential exists for the usage of cellulose fibers. Hemp fiber insulation was chosen due to its good hygrothermal and environmental performance (Kymäläinen and Sjöberg, 2008; Zampori et al., 2013). Additionally, hemp can be grown in 
moderate climates in contrast to other renewable insulation materials such as cotton stalks or pineapple leaves (Asdrubali et al., 2015). Foam glass was used to cover basement insulation demand, as the higher humidity levels prevent the use of insulation from renewable materials.

To estimate the shares of the different materials, the following assumptions were made (see chapter 2.2 in SI 1 for more detailed information):

- Replacement of $25 \%$ of the oil-based insulation materials with hemp. The calculated agricultural area to cover the hemp demand for insulation material would equal $0.4 \%$ of the total agricultural area of Switzerland.

- The remaining demand was split in equal parts between wood and cellulose. The amount of available waste wood for wood fiber insulation was calculated using the study done by Erni et al. (2017) under the assumption that waste wood is independent of the forest area as it often comes from imported products. For the development of available cellulose fibers, the low municipal solid waste scenario for waste paper amounts from Meylan et al. (2018) was used. These estimations resulted in the finding that wood and cellulose would be able to cover the required demand (Tables S3 - S6 in SI 1).

The global warming potential factors from Guest et al (2013) were used to account for the amount of biogenic carbon stored in the insulation. It was assumed that wood was first used as furniture (40 years), afterwards as insulation material (40 years), and finally incinerated for energy recovery. Hemp was assumed to be solely used for insulation. For cellulose fibers, the time in the system as paper was 3.8 years followed by the use as insulation material (Guest et al., 2013). An average life span of 40 years for insulation materials was assumed (Saadatian et al. 2016). To avoid double counting, the benefits of carbon stored during the first use (i.e. paper or furniture) were deducted from the total climate benefits of sequestered carbon for the respective material.

Stone wool and glass wool were assumed to be recycled to the same extent as in the increased recycling scenario.

\subsubsection{Assumptions for 'optimized' scenario}

We determined the use of oil-based materials to be environmentally favorable compared to the use of foamglass. Furthermore, foam-glass has a higher density and a higher thermal conductivity, resulting in a larger mass of material required to achieve the same insulation performance as oil-based materials. In the third scenario, therefore, oil-based materials were used in basements to ensure moisture protection, whereas renewable materials were used to replace oil-based insulation everywhere else. These oil-based materials 
and the mineral wools were assumed to be recycled to the same extent as in the increased recycling rate scenario.

\subsection{Phase 3: Evaluation of suggested measures for impact mitigation}

Based on the environmental assessment of the status quo and the comparison with the scenarios, strategies for impact mitigation are developed and discussed. A focus is laid on environmental aspects, which are discussed in-depth. Economic and social aspects are qualitatively discussed (Section 5).

To test the robustness of the obtained results, the influence of individual parameters on the calculated environmental impacts was determined by performing a sensitivity analysis on the following parameters.

- To determine the marginal electricity mixes' influence, calculations were redone with a different electricity mix for all life cycle stages of the insulation materials. For this electricity mix the marginal energy source was assumed to be natural gas (Bundesamt für Energie, 2007; Kirchner et al., 2012).

- The model of the amounts of insulation material installed and deconstructed takes into account many aspects such as population growth and legally required increased thermal insulation use. The calculations were repeated while taking into account a higher building refurbishment rate in combination with increased thermal insulation to lower heating greenhouse gas emissions in the use phase of buildings. This results in an increase of insulation material use (high turnover scenario in Heeren and Hellweg (2019)). The aim of this sensitivity analysis was to evaluate the effect on the environmental impacts but also to determine whether the available biomass or agricultural land in Switzerland is able to cover the increased demand in the scenarios 'increased use of renewable materials' and 'optimized'. 


\section{Results}

\subsection{Status Quo Assessment}

In Figure 2, the amounts of insulation material produced, installed, deconstructed, and disposed in the year 2015 are shown. Residues and contaminants are not displayed in this visualization. The complete MFA can be found in SI 1, Figure S2.

The circularity of the current system is low, namely 1.5\%. Current installation practice prevents deconstructed insulation material from ending up in single material troughs, as insulation material is glued, which hinders fast and residue-free separation. Even if material is collected in single material troughs, recycling systems currently only exist for EPS, stone wool, glass wool, and wood fiberboards. Oil-based materials are legally required to be incinerated due to HBCD contamination (UN Environment, 2017).

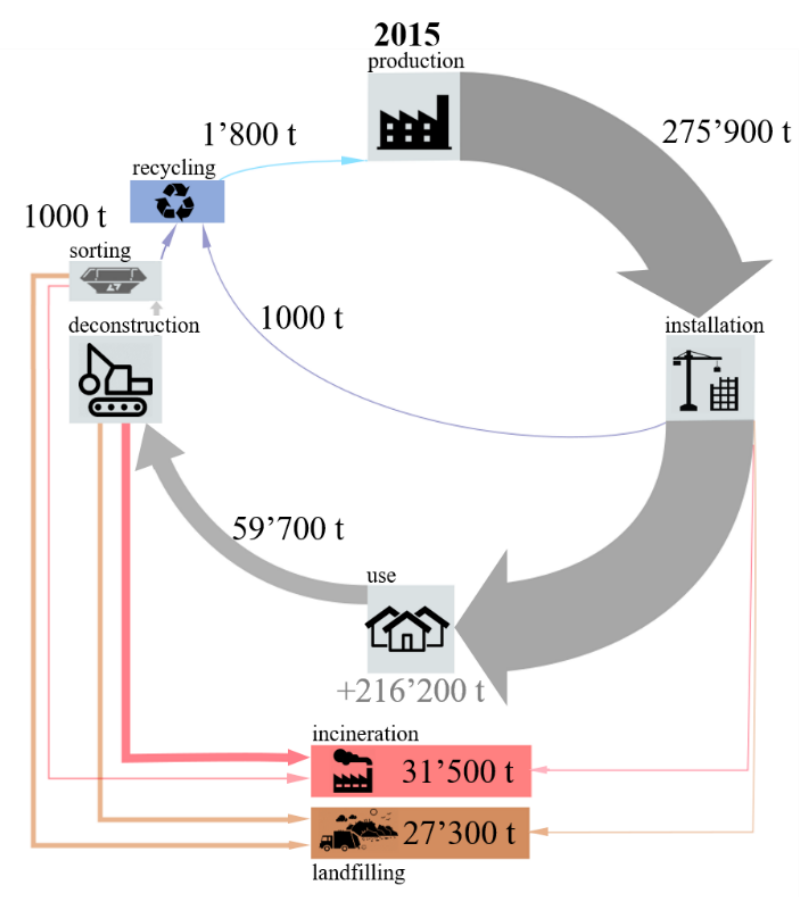

Figure 2: MFA of thermal insulation materials, without contaminants or residues, in Swiss residential buildings in 2015 . 
a)

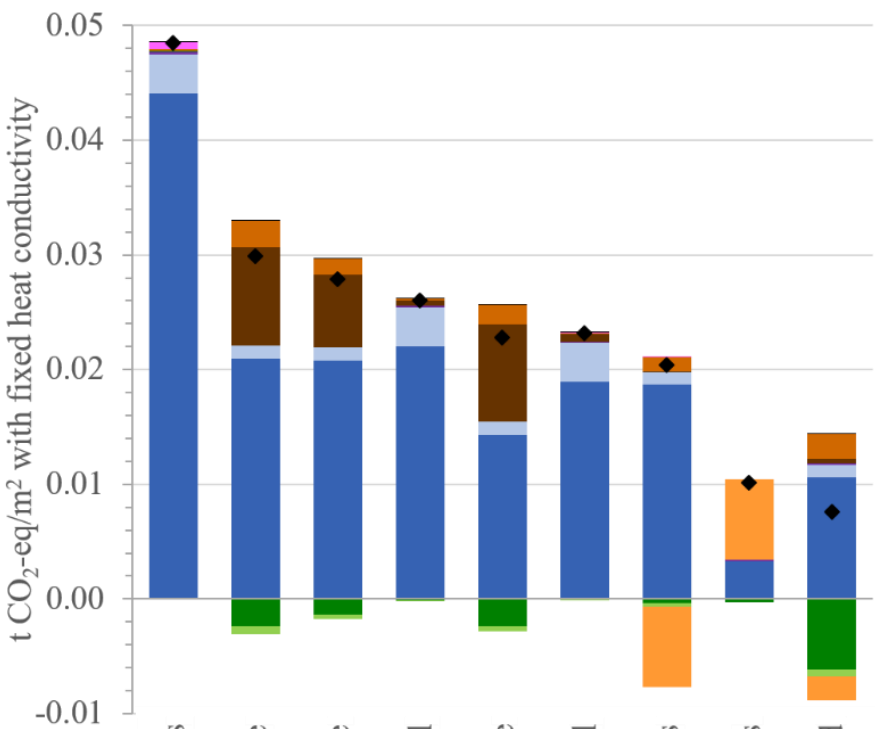

b)

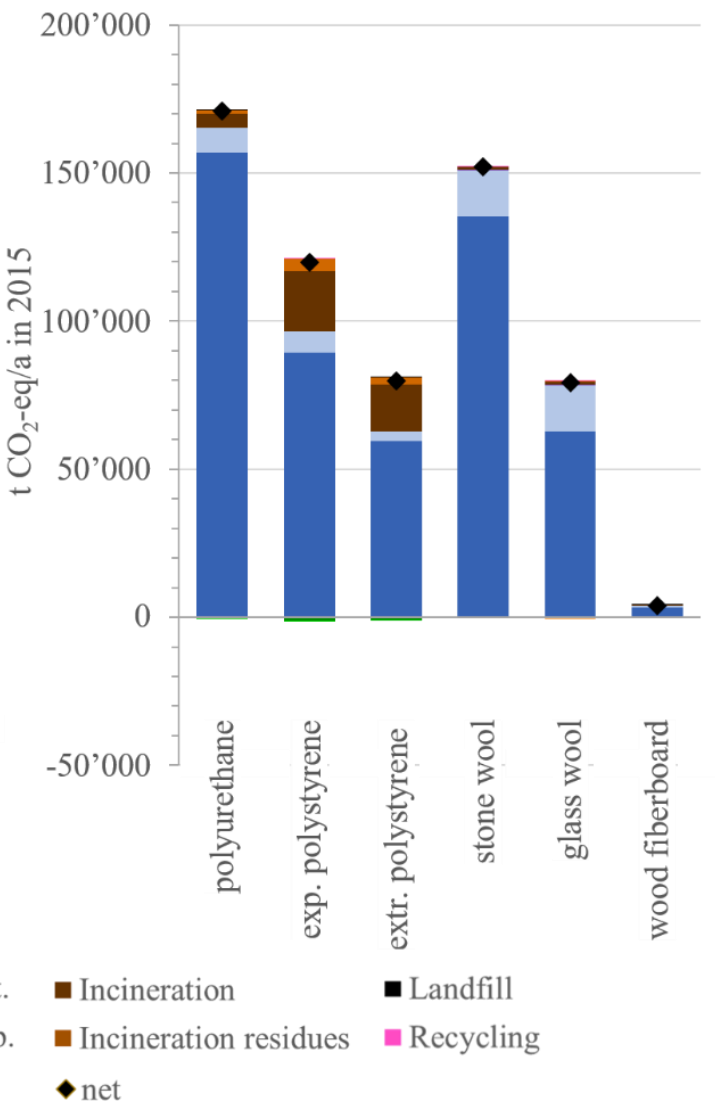

Figure 3: a) impact on climate change for different insulation materials per $m^{2}$ with fixed heat conductivity, and b) impact on climate change of the thermal insulation material in Swiss residential buildings for the year 2015. exp. $=$ expanded, extr. = extruded.

Figure 3 visualizes the impacts on climate change for each material normalized to one square meter of insulation material with a fixed heat conductivity (left) and the impacts on climate change for newly installed and deconstructed insulation materials in Swiss residential buildings in 2015 (right).

For oil-based materials, the most emission-intensive process is production, followed by the incineration of the material itself and then the incineration of the attached glue and plaster (Figure 3a). For mineral insulation materials, the environmental impact of production clearly surpasses the impacts caused by the end-of-life treatment (inert material landfill).

Considering the whole system (Figure 3b), the largest impacts are caused by the production of the insulation materials. It should be kept in mind that in 2015 a lot more material is installed than deconstructed, causing production impacts to be much higher than waste treatment processes. 


\subsection{Strategies for environmental impact reduction}

a)

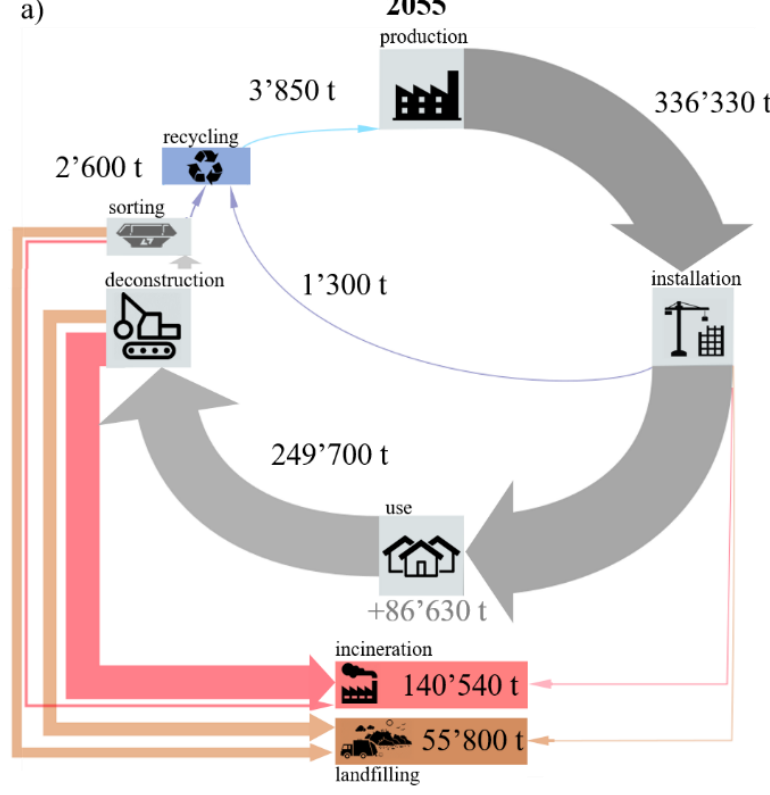

b)

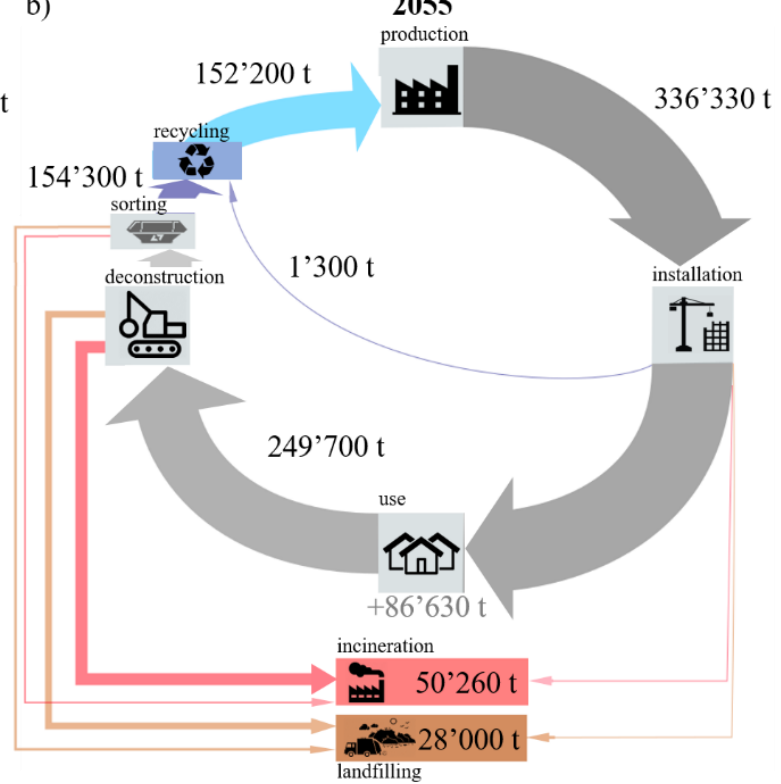

Figure 4: Comparison between insulation material flows in 2055 (a) for the baseline scenario and (b) increased recycling scenario.

The scenario 'increased recycling rate' entails the largest increase in material circularity. The biogenic insulation materials in the 'increased use of renewable materials' are mostly used in a cascade with energy recovery after their use as insulation material. The comparison of the material flows of the scenario 'increased recycling rate' and the continuation of the current practice in 2055 is presented in Figure 4.

Enhanced construction (screwing instead of gluing), improved separation during building deconstruction and increased collection in single material troughs facilitate increased recycling. These measures, together with the implementation of the flame retardant separating CreaSolv ${ }^{\circledR}$ process, lead to a circularity rate of $62 \%$ for all insulation materials in Switzerland in comparison to a circularity rate of $10 \%$ in 2055 in the baseline scenario (the MFA for the 'optimized' scenario for 2055 is displayed in Figure S3 in SI 1). 
Compared to the baseline scenario, a decrease of greenhouse gas (GHG) emissions for the 'increased recycling rate' scenario of $30 \%$ is seen (in 2055, Figure 5). For the 'increased use of renewable materials' scenario a decrease of $32 \%$ for 2055 is observed, while combining both scenarios as done in the 'optimized' scenario results in a decrease of $44 \%$ for 2055 .

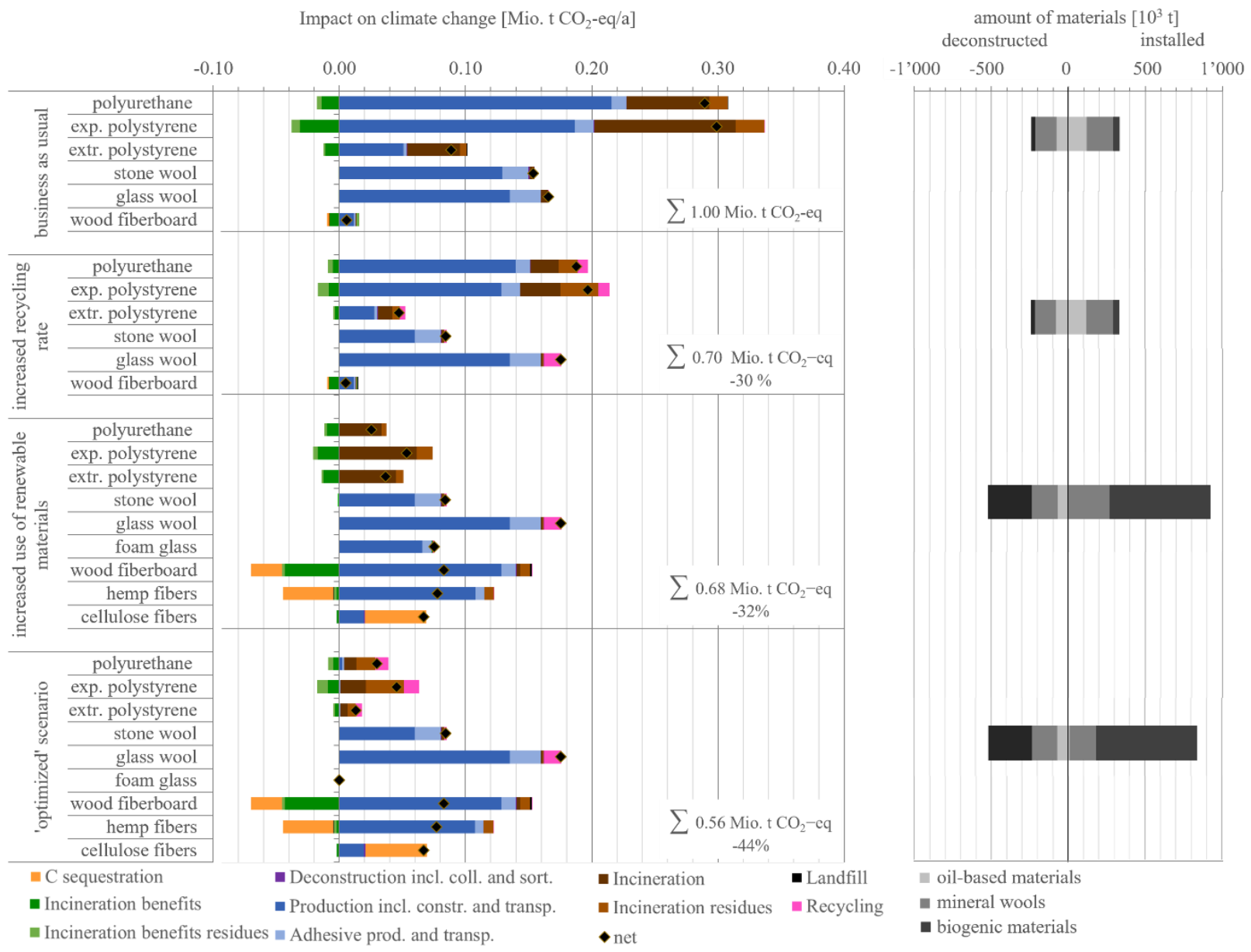

Figure 5: Left: Impact on climate change for the different scenarios 'Business as usual', (top) 'increased recycling rate' (middle top), 'increased use of renewable materials' (middle bottom), 'optimized" (bottom) for the year 2055 on the left side. Right: the amount of insulation material installed and deconstructed for the different scenarios.

For the 'increased recycling rate' scenario, the lower impact results from lower production volumes, i.e. a lower primary material input. The environmental impacts of the recycling process, i.e. the CreaSolv® process, are marginal compared to the savings in the production. For the 'increased use of renewable materials' scenario the impacts from the production of oil-based materials are reduced. As these insulation materials are replaced by renewables and foam glass, the impacts from the production of wood, hemp, and cellulose fibers, and foam glass increase. The emission of fossil $\mathrm{CO}_{2}$ from the incineration, however, can be avoided by using renewable materials. No foam glass is used in the 'optimized' scenario, leading to the differences in environmental impacts compared to the 'increased use of renewable materials' scenario. 
The variation to the baseline scenario impacts in the category USEtox human toxicity are similar to the impacts on climate change, with the optimized scenario having the lowest impacts. For the use of hemp, a credit is given for the uptake of heavy metals in the hemp plant during its growth (see Figure S5 in SI). In absolute terms, the uptake of heavy metals by plants is irrelevant, showing that the human toxicity impacts are negligible. The increased impacts with regard to ecotoxicity (see Figure S6 in SI) of the scenario 'increased use of renewable materials' can be traced back to the production of foam glass, i.e. the consumption of electricity and molybdenum, and the use of hemp fibers, i.e. the required energy for irrigation. Again, processes far back in the supply chain dominate, showing that this impact category does not contribute significantly to the overall environmental impacts. The expansion agent was assumed to be $\mathrm{CO}_{2}$, and no CFCs or HFCs were emitted during the use phase of the oil-based materials, therefore the impacts on 'ozone layer depletion' can also be considered negligible. The impact categories terrestrial eutrophication and land use show similar results, with only the scenario 'increased recycling rate' leading to a decrease in impacts. The other two scenarios lead to elevated impacts due to the cultivation of hemp, requiring land and fertilizer.

Figure 5 (right) shows the installed and deconstructed amounts of insulation material for each scenario. While recycling leads to reduced material consumption, a substitution of oil-based insulation material with other materials leads to an increased mass of installed insulation but still reduced environmental impact.

\subsection{Sensitivity Analysis}

- The influence of including natural gas in the electricity mix as compared to a completely renewable mix was minimal, i.e. for the continuation of current practice the difference was $0.03 \%$. The small difference is a result of the low electricity consumption and hence small impacts. The development of the electricity mix is therefore not a decisive parameter for the assessment of insulation systems.

- Using the high-turnover scenario data resulted in an increased input of insulation materials of $9 \%$ and $11 \%$ for 2035 and 2055 , respectively, and an increase in output of $15 \%$ for both time horizons. The impacts of the different scenarios change proportionally to the increase of insulation material used; hence the relative improvement potentials stay the same. The detailed changes in impacts for the different scenarios and time horizons with high turnover amounts are presented in Table S14 in the SI 1. The available amount of waste paper and waste wood was determined sufficient to cover the demand of waste paper and waste wood in the high-turnover scenario (Table S6). 


\section{Discussion}

The results of the case study show that the current material circularity of insulation materials in Switzerland is low. To increase the circularity, circular system design aspects, i.e. reversible building construction, better separation onsite, and a process for the separation of insulation material and flame retardant need to be considered. The environmental impacts of the assessed system can be reduced through either increased recycling (-30\%), replacement of oil-based materials with renewable materials (-32\%), or a combination of both $(-44 \%)$. Overall, primary production and incineration of insulation materials and their adhering residues were determined to be the most impact-intensive processes. To reduce environmental impacts, (i) recycling should be increased and (ii) materials with lower impacts in production and in thermal treatment, i.e. renewable materials, should be chosen.

\subsection{Construction and deconstruction practice}

Lacking recycling systems and incentives for recycling, current installation and deconstruction practices, as well as the legally required incineration of oil-based insulation materials all contribute to the aforementioned low material circularity. Current installation practice includes gluing insulation material to walls, for it is the fastest and thus cheapest installation practice. With current deconstruction practice, insulation materials are only roughly separated from mineral materials. This leads to only a small amount of material collected in single material troughs and subsequently little recycling. The collected material needs to then be separated from the adhesives, resulting in higher efforts to recycle. Instead of gluing, insulation could be bolted, which would facilitate the separation of the insulation material from the glue but not the separation from the mineral materials.

One approach for increased recycling might be the use of foamed mineral insulation materials, produced from construction waste (Van der Haegen, 2019). This mineral insulation material may be deconstructed and sorted similarly to the rest of the mineral materials as it consists mainly of recycled construction waste. Foamed mineral insulation materials could be produced by construction or deconstruction companies and hence also be installed, deconstructed, and recycled with the rest of the mineral construction materials. Such technologies are in development, but do not yet exist at full scale (Van der Haegen, 2019).

Alternatively, fibrous materials such as cellulose fibers, are blown into and out of hollow spaces in a building, which enables their direct collection as a single material and avoids adhesive residues (isofloc AG, 2019). 


\subsection{Incentives for increased recycling}

The current recycling scheme assigns the recycling costs completely to the deconstructing party. An advanced recycling fee, paid when purchasing insulation material, would switch the financial burden of the recycling to the customer. This is a concept that has been proven to be useful, environmentally and economically, in the context of waste electric an electronic equipment in Switzerland (Der Schweizerische Bundesrat, 2006; Kägi and Franov, 2016). The introduction of an advanced recycling fee would remove the financial burden of recycling from deconstruction companies and remove a barrier to collect and recycle used insulation materials.

\subsection{Value retention beyond recycling}

Within the circularity strategies, recycling (R8) is a less preferable option and strategies further up in the hierarchy should be considered (Potting et al., 2016). However, reducing (R2) the use of insulation material is not an option as the energy savings from the use of insulation systems exceed the energy consumed during the production (Al-Homoud, 2005). The reuse (R3) of insulation material would require modular construction practices, enabling easy assembly and disassembly of construction materials. One often mentioned strategy for increased reuse would be to establish a service oriented model (see for example Witjes and Lozano (2016) and Bocken et al. (2016)), i.e. the leasing of insulation materials. This, however, would be difficult to implement, due to the long life spans of the material in buildings. Consequently, in the short-term perspective enabling increased recycling of insulation material will have the largest impacts on circularity. To ensure increased circularity in the future, options, such as modular construction and leasing, should be considered for optimal resource use.

\subsection{Cascading and carbon sequestration of biogenic materials}

Besides being less impact-intensive in production, wood and cellulose fiber insulations have the additional advantage of being made of waste materials. Both materials can still be used for energy production after their lifetime as insulation material.

The longer wood, hemp, or cellulose fibers are used, the longer carbon is stored in the materials while plants can regrow and sequester carbon.

Biogenic materials, if not produced from waste, may however produce adverse impacts with regard to land use and eutrophication. The risk that hemp plantation could be in competition with food production was assumed to be limited as only $0.4 \%$ of the total agricultural land would be required to meet the assumed demand. 


\subsection{Costs}

Materials from renewable sources are generally more expensive than mineral materials and oil-based materials (see Table S13). Using materials with lower environmental impacts is therefore often related to higher costs. Legal requirements currently only focus on insulation capacity, with no regard to the type of material. Besides environmental awareness no driver for the selection of materials with lower impacts is present. Many multi-family residential buildings are built by enterprises focusing mostly on profit, hence opting for the insulation materials with the best cost-performance ratio. For private single-family homes in Switzerland it depends on the budget and willingness of the owner which material is chosen.

\subsection{Health impacts}

Health risks of workers and occupants were not assessed in the case study. The health effects of stone and glass wool fibers on the workers were evaluated in previous studies, concluding that the fibers might be potentially carcinogenic (Berrigan, 2002; Lipworth et al., 2009; McConnell et al., 1994). The type of binder used in the mineral wools influences the dissolution rate of the fibers (which is related to the onset of cancer). As the binder composition changed in the last decade, health risks related to glass and stone wool fibers should be reevaluated (Wohlleben et al., 2017).

\section{Conclusion}

The presented SCSD approach provides a comprehensive assessment of material flows, environmental impacts and circular economy strategies. Most importantly, the combined assessment of material circularity and environmental impacts prevents unsustainable, yet circular, solutions. The suggested three phases, of which every phase entails clearly defined goals, allows for a structured approach for circular and sustainable system design. An advantage of the suggested SCSD approach lies in using established methods, whose applications are well known. Following the three phases allows for the design and assessment of new products and systems; environmental hotspots are detected and afterwards improvement measures developed.

The modeling of impurities and contaminants was shown to be of great importance in the case study. Hence, for other case studies, we recommend to likewise model these, as they can be decisive in terms of environmental impacts and represent a barrier for circular solutions. In the environmental comparison of scenarios, we were also able to show that the lowest mass of resource consumption does not necessarily 
lead to the largest environmental impact reduction. This highlights that sole mass-based assessment is not enough to identify the best circularity option.

The SCSD method was applied on a rather simple case study with only one value retention process. The methodology can also deal with other Rs, such as reuse, repair, etc. which have not been included in this study.

The investigation of all system interactions poses a challenge, not just for the SCSD approach, but for environmental assessments of systems in general. For example, different building types (e.g. solid wood construction) or the effect on the building frame when using heavier or more insulation material were not considered in this study.

By applying the method to the case study, the following generally applicable conclusions for SCSD can be drawn:

1. Products should be designed free of hazardous substances, as also promoted in other studies, otherwise recycling is either not possible, more costly (in monetary and environmental terms), or it may result in unwanted exposure to pollutants in the products made from the recycling material. Contaminants should be removed from the cycle and put to a final sink (Kral et al., 2019, 2013).

2. The fate of the product when reaching its end of life should be studied at the beginning of the design process. Products than can be easily separated from other materials are much easier to reuse, recycle, etc. Easier dismantling would additionally facilitate repairing and/or remanufacturing and/or refurbishing. Product designers have a large leverage in enabling circularity strategies.

3. Concerning impacts on climate change, biogenic materials from waste should be considered when choosing materials as they demonstrated advantages in the form of carbon sequestration and low production impacts.

In conclusion, the three aspects of contaminants, end of life, and type of materials are crucial when aiming at designing a more sustainable and circular system. We demonstrated that our SCSD approach is a suitable means to support structured sustainable circular systems design for existing or newly designed systems.

\section{Author contributions}

The manuscript was written through contributions of all authors. All authors have given approval to the final version of the manuscript. 


\section{Acknowledgments}

This study was supported by the Swiss National Science Foundation (SNSF) within the framework of the National Research Programme "Sustainable Economy: resource-friendly, future-oriented, innovative" (NRP 73) Grant-N ${ }^{\circ} 407340 \_172456$. Further information can be found at http://www.nrp73.ch

We would also like to thank all our industry partners for providing data and advice. Our thanks also go to the reviewer for providing helpful inputs, Stephan Pfister for the internal review and to Christie Walker for proofreading the manuscript.

\section{Appendix - Supporting Information}

See word file for supporting information 1 and excel table for supporting information 2. 


\section{Bibliography}

Al-Homoud, D.M.S., 2005. Performance characteristics and practical applications of common building thermal insulation materials. Build. Environ. 40, 353-366. https://doi.org/https://doi.org/10.1016/j.buildenv.2004.05.013

Asdrubali, F., D’Alessandro, F., Schiavoni, S., 2015. A review of unconventional sustainable building insulation materials. Sustain. Mater. Technol. https://doi.org/10.1016/j.susmat.2015.05.002

BAFU, 2018. Klimapolitik in der Schweiz. Umsetzung des Übereinkommens von Paris. Bern.

Berrigan, D., 2002. Respiratory cancer and exposure to man-made vitreous fibers: A systematic review. Am. J. Ind. Med. https://doi.org/10.1002/ajim.10111

Bocken, N.M.P., de Pauw, I., Bakker, C., van der Grinten, B., 2016. Product design and business model strategies for a circular economy. J. Ind. Prod. Eng. https://doi.org/10.1080/21681015.2016.1172124

Boesch, M.E., Vadenbo, C., Saner, D., Huter, C., Hellweg, S., 2014. An LCA model for waste incineration enhanced with new technologies for metal recovery and application to the case of Switzerland. Waste Manag. 34, 378-389. https://doi.org/https://doi.org/10.1016/j.wasman.2013.10.019

Brandão, M., Levasseur, A., Kirschbaum, M.U.F., Weidema, B.P., Cowie, A.L., Jørgensen, S.V., Hauschild, M.Z., Pennington, D.W., Chomkhamsri, K., 2013. Key issues and options in accounting for carbon sequestration and temporary storage in life cycle assessment and carbon footprinting. Int. J. Life Cycle Assess. 18, 230-240. https://doi.org/10.1007/s11367-012-0451-6

Brunner, P., Rechberger, H., 2010. Methodology of MFA, in: Practical Handbook of Material Flow Analysis. https://doi.org/10.1201/9780203507209.ch2

Brunner, P.H., Rechberger, H., 2015. Waste to energy - key element for sustainable waste management. Waste Manag. https://doi.org/10.1016/j.wasman.2014.02.003

Brupbacher, A., Rubli, S., 2016. Entsorgungssituation von Dämmmaterialien in der Schweiz. Bern.

Bundesamt für Energie (BFE), 2007. Die Energieperspektiven 2035 - Band 2 Szenarien I bis IV, Energieperspektiven 2035.

Cencic, O., Rechberger, H., 2008. Material Flow Analysis with Software STAN. Environ. Informatics Ind. Ecol.

Cobo, S., Dominguez-Ramos, A., Irabien, A., 2018. From linear to circular integrated waste management 
systems: A review of methodological approaches. Resour. Conserv. Recycl. 135, 279-295. https://doi.org/https://doi.org/10.1016/j.resconrec.2017.08.003

Der Schweizerischen Bundesrat, 2006. Verordnung über die Rückgabe, die Rücknahme und die Entsorgung elektrischer und elektronischer Geräte (VREG) 2006, 3-6.

Ekvall, T., Weidema, B.P., 2004. System boundaries and input data in consequential life cycle inventory analysis, in: International Journal of Life Cycle Assessment. https://doi.org/10.1007/BF02994190

Ellen MacArthur Foundation, 2013. Towards the Circular Economy.

Erni, M., Thees, O., Lemm, R., 2017. Altholzpotenziale der Schweiz für die energetische Nutzung. Birmensdorf.

European Commission, 2011. ILCD handbook, International Reference Life Cycle Data System (ILCD) Handbook, Recommendations for life cycle impact assessment in the European context. https://doi.org/10.2788/33030

Freegard, K., Tan, G., Morton, R., Coggins, C., Froes, D., Alger, M., Cracknell, P., Maeurer, A., Studds, P., Freer, E., Huisman, J., 2006. Develop a process to separate brominated flame retardants from WEEE polymerr, Waste \& Resources Action Programme.

Ghisellini, P., Cialani, C., Ulgiati, S., 2016. A review on circular economy: the expected transition to a balanced interplay of environmental and economic systems. J. Clean. Prod. 114, 11-32. https://doi.org/https://doi.org/10.1016/j.jclepro.2015.09.007

Greenpeace, 2015. Energy Revolution. Energy [R]Evolution.

Guest, G., Bright, R.M., Cherubini, F., Strømman, A.H., 2013. Consistent quantification of climate impacts due to biogenic carbon storage across a range of bio-product systems. Environ. Impact Assess. Rev. 43, 21-30. https://doi.org/https://doi.org/10.1016/j.eiar.2013.05.002

Hahladakis, J.N., Iacovidou, E., 2018. Closing the loop on plastic packaging materials: What is quality and how does it affect their circularity? Sci. Total Environ. https://doi.org/10.1016/j.scitotenv.2018.02.330

Haupt, M., Hellweg, S., 2019. Measuring the environmental sustainability of a circular economy. Environ. Sustain. Indic. 1-2, 100005. https://doi.org/https://doi.org/10.1016/j.indic.2019.100005

Haupt, M., Kägi, T., Hellweg, S., 2018. Modular life cycle assessment of municipal solid waste management. Waste Manag. https://doi.org/10.1016/j.wasman.2018.03.035 
Haupt, M., Vadenbo, C., Hellweg, S., 2016. Do We Have the Right Performance Indicators for the Circular Economy?: Insight into the Swiss Waste Management System. J. Ind. Ecol. 21, 615-627. https://doi.org/10.1111/jiec.12506

Haupt, M., Vadenbo, C., Zeltner, C., Hellweg, S., 2017. Influence of Input-Scrap Quality on the Environmental Impact of Secondary Steel Production. J. Ind. Ecol. https://doi.org/10.1111/jiec.12439

Haupt, M., Zschokke, M., 2017. How can LCA support the circular economy?-63rd discussion forum on life cycle assessment, Zurich, Switzerland, November 30, 2016. Int. J. Life Cycle Assess. https://doi.org/10.1007/s11367-017-1267-1

Heeren, N., Hellweg, S., 2019. Tracking Construction Material over Space and Time: Prospective and Georeferenced Modeling of Building Stocks and Construction Material Flows. J. Ind. Ecol. https://doi.org/10.1111/jiec.12739

Hellweg, S., Milà i Canals, L., 2014. Emerging approaches, challenges and opportunities in life cycle assessment. Science (80-. ). 344, 1109-1113. https://doi.org/10.1126/science.1248361

Homrich, A.S., Galvão, G., Abadia, L.G., Carvalho, M.M., 2018. The circular economy umbrella: Trends and gaps on integrating pathways. J. Clean. Prod. 175, 525-543. https://doi.org/https://doi.org/10.1016/j.jclepro.2017.11.064

Huysman, S., De Schaepmeester, J., Ragaert, K., Dewulf, J., De Meester, S., 2017. Performance indicators for a circular economy: A case study on post-industrial plastic waste. Resour. Conserv. Recycl. 120, 46-54. https://doi.org/10.1016/J.RESCONREC.2017.01.013

IPCC, 2013. Summary for Policymakers. In: Climate Change 2013: The Physical Science Basis. Contribution of Working Group I to the Fifth Assessment Report of the Intergovernmental Panel on Climate Change. CEUR Workshop Proc. https://doi.org/10.1017/CBO9781107415324.004

IRP, Oberle, B., Bringezu, S., Hatfield-dodds, S., Hellweg, S., Schandl, H., Clement, J., Authors, C., Cabernard, L., Che, N., Chen, D., Droz-georget, H., Ekins, P., Fischer-kowalski, M., Flörke, M., Frank, S., Froemelt, A., Geschke, A., Haupt, M., Havlik, P., Hüfner, R., Lenzen, M., Lieber, M., Liu, B., Lu, Y., Lutter, S., Mehr, J., Miatto, A., Newth, D., Oberschelp, C., Pfister, S., Piccoli, E., Schaldach, R., Schüngel, J., Sonderegger, T., Sudheshwar, A., Voet, E. Van Der, Walker, C., West, J., Wang, Z., Zhu, B., 2019. Global Resources Outlook 2019: Natural Resources for the Future We Want.

isofloc AG, 2019. isofloc [WWW Document]. URL https://isofloc.ch/de/unsere-daemmprodukte-2/ 
(accessed 11.8.18).

ISOVER St. Gobain, 2018. ISOVER Recycling - les déchets de laine de verre ont désormais und filière de recyclage - Dossier de presse.

Jakob, M., Rubli, S., Sunarjo, B., 2016. Dämmmaterialien im Gebäudepark der Schweiz - Eine Bestandesaufnahme. Zürich.

Kägi, T., Franov, E., 2016. Ökobilanz Stiftung SENS Ökologischer Nutzen des Elektrogeräte-Recyclings durch die SENS über 25 Jahre. Basel.

Kasser, U., Klingler, M., Savi, D., 2013. HBCD als Flammschutz in Polystyrol - Zusammenfassung. Zürich.

Kirchherr, J., Reike, D., Hekkert, M., 2017. Conceptualizing the circular economy: An analysis of 114 $\begin{array}{llll}\text { definitions. } & \text { Resour. } & \text { Conserv. } & \text { Recycl. }\end{array}$ https://doi.org/https://doi.org/10.1016/j.resconrec.2017.09.005

Kirchner, A., Ess, F., Grebel, T., Hofer, P., Kemmler, A., Ley, A., Piégsa, A., Schütz, N., Strassburg, S., Struwe, J., Daniel, B., 2012. Die Energieperspektiven für die Schweiz bis 2050 - Energienachfrage und Elektrizitätsangebot in der Schweiz 2000 - 2050. Bundesamt für Energ.

Kral, U., Kellner, K., Brunner, P.H., 2013. Sustainable resource use requires “clean cycles” and safe "final sinks.” Sci. Total Environ. https://doi.org/10.1016/j.scitotenv.2012.08.094

Kral, U., Morf, L.S., Vyzinkarova, D., Brunner, P.H., 2019. Cycles and sinks: two key elements of a circular economy. J. Mater. Cycles Waste Manag. https://doi.org/10.1007/s10163-018-0786-6

Kymäläinen, H.R., Sjöberg, A.M., 2008. Flax and hemp fibres as raw materials for thermal insulations. Build. Environ. https://doi.org/10.1016/j.buildenv.2007.03.006

Leslie, H.A., Leonards, P.E.G., Brandsma, S.H., de Boer, J., Jonkers, N., 2016. Propelling plastics into the circular economy - weeding out the toxics first. Environ. Int. https://doi.org/10.1016/j.envint.2016.05.012

Lipworth, L., La Vecchia, C., Bosetti, C., McLaughlin, J.K., 2009. Occupational Exposure to Rock Wool and Glass Wool and Risk of Cancers of the Lung and the Head and Neck: A Systematic Review and Meta-Analysis. J. Occup. Environ. Med. 51.

Martinez-Sanchez, V., Kromann, M.A., Astrup, T.F., 2015. Life cycle costing of waste management systems: Overview, calculation principles and case studies. Waste Manag. 36, 343-355. https://doi.org/https://doi.org/10.1016/j.wasman.2014.10.033 
Martinez-Sanchez, V., Levis, J.W., Damgaard, A., DeCarolis, J.F., Barlaz, M.A., Astrup, T.F., 2017. Evaluation of Externality Costs in Life-Cycle Optimization of Municipal Solid Waste Management Systems. Environ. Sci. Technol. https://doi.org/10.1021/acs.est.6b06125

Massarutto, A., Carli, A. de, Graffi, M., 2011. Material and energy recovery in integrated waste management systems: A life-cycle costing approach. Waste Manag. 31, 2102-2111. https://doi.org/10.1016/J.WASMAN.2011.05.017

McConnell, E.E., Kamstrup, O., Musselman, R., Hesterberg, T.W., Chevalier, J., Miiller, W.C., Thevenaz, P., 1994. Chronic Inhalation Study of Size-Separated Rock and Slag Wool Insulation Fibers in Fischer 344/N Rats. Inhal. Toxicol. 6, 571-614. https://doi.org/10.3109/08958379409003042

Meylan, G., Haupt, M., Duygan, M., Hellweg, S., Stauffacher, M., 2018. Linking energy scenarios and waste storylines for prospective environmental assessment of waste management systems. Waste Manag. 81, 11-21. https://doi.org/https://doi.org/10.1016/j.wasman.2018.09.017

Morf, L., Buser, A., Taverna, R., 2007. Dynamic Substance Flow Analysis Model for Selected Brominated Flame Retardants as a Base for Decision Making on Risk Reduction Measures (FABRO) - Final Report. GeoPartner AG Resource Management.

Münster, M., Ravn, H., Hedegaard, K., Juul, N., Ljunggren Söderman, M., 2015. Economic and environmental optimization of waste treatment. Waste Manag. 38, 486-495. https://doi.org/10.1016/J.WASMAN.2014.12.005

Mutel, C., 2017. Brightway: An open source framework for Life Cycle Assessment. J. Open Source Softw. https://doi.org/10.21105/joss.00236

Pauliuk, S., Hasan, M., 2017. Circular Sankey.

Pauliuk, S., Kondo, Y., Nakamura, S., Nakajima, K., 2017. Regional distribution and losses of end-of-life steel throughout multiple product life cycles-Insights from the global multiregional MaTrace model. Resour. Conserv. Recycl. https://doi.org/10.1016/j.resconrec.2016.09.029

PAVATEX SA, n.d. Bauen und Wohnen mit der Natur.

Pivnenko, K., Laner, D., Astrup, T.F., 2016. Material Cycles and Chemicals: Dynamic Material Flow Analysis of Contaminants in Paper Recycling. Environ. Sci. Technol. 50, 12302-12311. https://doi.org/10.1021/acs.est.6b01791

Potting, J., Hekkert, M., Worrell, E., Hanemaaijer, A., 2016. Circular Economy : Measuring innovation in 
product chains. The Hague.

Rosenbaum, R.K., Bachmann, T.M., Gold, L.S., Huijbregts, M.A.J., Jolliet, O., Juraske, R., Koehler, A., Larsen, H.F., MacLeod, M., Margni, M., McKone, T.E., Payet, J., Schuhmacher, M., van de Meent, D., Hauschild, M.Z., 2008. USEtox---the UNEP-SETAC toxicity model: recommended characterisation factors for human toxicity and freshwater ecotoxicity in life cycle impact assessment. Int. J. Life Cycle Assess. 13, 532. https://doi.org/10.1007/s11367-008-0038-4

Saadatian, S.S., Freire, F., Simões, N., 2016. Comparative Life-Cycle Analysis of Insulation Materials in A Dwelling, Addressing Alternative Heating Systems and Life Spans. J. Clean Energy Technol. 4, 462-465. https://doi.org/10.18178/jocet.2016.4.6.333

Satchatippavarn, S., Martinez-Hernandez, E., Hang, M.Y.L.P., Leach, M., Yang, A., 2016. Urban biorefinery for waste processing. Chem. Eng. Res. Des. 107, 81-90. https://doi.org/https://doi.org/10.1016/j.cherd.2015.09.022

Schiavoni, S., D’Alessandro, F., Bianchi, F., Asdrubali, F., 2016. Insulation materials for the building sector: A review and comparative analysis. Renew. Sustain. Energy Rev. https://doi.org/10.1016/j.rser.2016.05.045

Schlummer, M., Maurer, A., Wagner, S., Berrang, A., Fell, T., Knappich, F., 2017. Recycling of flame retarded waste polystyrene foams (EPS and XPS) to PS granules free of hexabromocyclododecane (HBCDD). Adv. Recycl. Waste Manag. https://doi.org/10.4172/2475-7675.1000131

Tonini, D., Dorini, G., Astrup, T.F., 2014. Bioenergy, material, and nutrients recovery from household waste: Advanced material, substance, energy, and cost flow analysis of a waste refinery process. Appl. Energy 121, 64-78. https://doi.org/https://doi.org/10.1016/j.apenergy.2014.01.058

UN Environment, 2017. The 16 New POPs, in: Stockholm Convention on Persistent Organic Pollutants (POPs).

UNEP, 2018. Push to pock up the pace on the circular economy [WWW Document]. Int. Resour. Panel. URL http://www.resourcepanel.org/news-events/push-pick-pace-circular-economy (accessed 7.27.18).

UNEP, 2011. Decoupling Natural Resource Use and Environmental Impacts from Economic Growth, International Resource Panel.

UVEK, 2017. Faktenblatt "Energie sparen und Energieeffizienz erhöhen." 
Vadenbo, C., Guillén-Gosálbez, G., Saner, D., Hellweg, S., 2014a. Multi-objective optimization of waste and resource management in industrial networks - Part II: Model application to the treatment of sewage sludge. Resour. Conserv. Recycl. 89, 41-51. https://doi.org/10.1016/J.RESCONREC.2014.05.009

Vadenbo, C., Hellweg, S., Astrup, T.F., 2017. Let's Be Clear(er) about Substitution: A Reporting Framework to Account for Product Displacement in Life Cycle Assessment. J. Ind. Ecol. 21, 10781089. https://doi.org/10.1111/jiec.12519

Vadenbo, C., Hellweg, S., Guillén-Gosálbez, G., 2014b. Multi-objective optimization of waste and resource management in industrial networks - Part I: Model description. Resour. Conserv. Recycl. 89, 52-63. https://doi.org/10.1016/J.RESCONREC.2014.05.010

Van der Haegen, P., 2019. Personal Communication.

Villiger, M., 2018. Personal Communication.

Waser, E., 2017. Analyse der ökologischen Relevanz und des Potentials von Dämmstoffabfällen in der Schweiz. Master Thesis ETH Zurich.

Weidema, B., Wenzel, H., Petersen, C., Hansen, K., 2004. The product, functional unit and reference flows in LCA. Danish Minist. Environ. Environ. News. https://doi.org/10.1159/000169769

Wernet, G., Bauer, C., Steubing, B., Reinhard, J., Moreno-Ruiz, E., Weidema, B., 2016. The ecoinvent database version 3 (part I): overview and methodology. Int. J. Life Cycle Assess. https://doi.org/10.1007/s11367-016-1087-8

Winans, K., Kendall, A., Deng, H., 2017. The history and current applications of the circular economy $\begin{array}{lllll}\text { concept. } & \text { Renew. } & \text { Sustain. }\end{array}$ https://doi.org/https://doi.org/10.1016/j.rser.2016.09.123

Witjes, S., Lozano, R., 2016. Towards a more Circular Economy: Proposing a framework linking sustainable public procurement and sustainable business models. Resour. Conserv. Recycl. 112, 3744. https://doi.org/https://doi.org/10.1016/j.resconrec.2016.04.015

Wohlleben, W., Waindok, H., Daumann, B., Werle, K., Drum, M., Egenolf, H., 2017. Composition, Respirable Fraction and Dissolution Rate of 24 Stone Wool MMVF with their Binder. Part. Fibre Toxicol. 14, 29. https://doi.org/10.1186/s12989-017-0210-8

Zampori, L., Dotelli, G., Vernelli, V., 2013. Life Cycle Assessment of Hemp Cultivation and Use of Hemp- 
Based Thermal Insulator Materials in Buildings. Environ. Sci. Technol. 47, 7413-7420. https://doi.org/10.1021/es401326a

Zink, T., Geyer, R., 2017. Circular Economy Rebound. J. Ind. Ecol. 21, 593-602. https://doi.org/10.1111/jiec.12545 